\title{
IMAGERY AND GENDER IN CANADIAN ENGINEERING RECRUITMENT DOCUMENTS
}

\author{
Agnes d'Entremont ${ }^{1}$, Kerry Greer ${ }^{2}$, Katherine Lyon ${ }^{2}$, Diana Demmers ${ }^{3}$, and Kaitlyn Wamsteeker ${ }^{2}$ \\ Departments of ${ }^{1}$ Mechanical Engineering, ${ }^{2}$ Sociology, and ${ }^{3}$ Civil Engineering, University of British Columbia \\ agnes.dentremont@mech.ubc.ca, kerry.greer@ubc.ca
}

\begin{abstract}
Gender imbalance is a persistent issue across Canadian engineering programs. Efforts have been made to increase the enrolment of undergraduate women in engineering, but reaching gender parity in engineering has been an elusive goal. This research examines program recruitment images and videos from 18 Canadian engineering university websites. Using content analysis and thematic coding of video transcriptions, we coded 440 unique images and 37 recruitment videos. We find that women students are overrepresented in images and in videos, at rates higher than we expect given their proportion within programs. We compare the presentation of women and men across several dimensions and identify key differences in women's representation in relevant settings, attire, and in the kinds of learning experiences they emphasize in videos. We conclude with suggestions for ways programs can present a more neutral portrayal of women in recruitment materials.
\end{abstract}

Keywords: Gender, recruitment, images, videos, content analysis, undergraduate engineering

\section{INTRODUCTION}

Significant gender imbalance exists in nearly every undergraduate engineering faculty in Canada [1], despite efforts to increase the numbers of women in engineering. Much of the discrepancy is attributed to lower recruitment of women. Our aim was to examine images and videos used in recruitment materials by engineering schools in an effort to better understand what they portray about women and engineering.

Building on a previous study [2] that established a positive correlation between feminine wording in recruitment material and the percentage of female faculty members, this research examines how gender is depicted in images and videos targeted at prospective students.

This research takes as its starting point that context matters - that what people are doing, where they are, who they are with, and how they are represented matters, particularly in terms of signaling the expectations around gender and the performance of gender roles. Status signals, such as indicating a person's industrial affiliation or educational credentials, or whether someone is depicted holding a scientific instrument or looking on as someone else holds it, are important clues to how gender is constructed in a particular place and time. We approached this project as "gender detectives" with the goal of finding out if traditional depictions of gender are being reproduced that contradict the broader goal of achieving gender parity in engineering.

We hypothesized that the representation of women in public-facing recruitment material would tend to slightly over represent women, compared to their enrolment in the program, in an effort to present engineering as a place where women belong. We also expected that women and men would be depicted in similar ways (similar settings, activities, etc.). To test these hypotheses, we examined images and videos from website materials aimed at recruiting undergraduate students across a sample of 18 English-language Canadian accredited engineering schools.

By analyzing the number of women and men students represented by attire (business, safety attire), setting (classroom, laboratory, worksite), activity (using tools, writing, etc.), the length of time each person is present in videos, and by qualitatively coding the video transcripts, we found: a) women students are disproportionally overrepresented in images and videos (including among those speaking and among those with the longest screen times); b) women students are visible in expected proportions in the settings of classroom and laboratory, but are in a much higher proportion of images in settings irrelevant to engineering; c) women students are more frequently wearing safety clothing, but less frequently wearing business clothing; and d) women students are more frequently guiding others, and less frequently using computers and tablets than expected by their proportion in imagery.

These results suggest that Canadian engineering schools are consciously trying to include women students doing engineering work in their public facing website materials, but that those materials should be reviewed carefully, with attention paid to the details of setting, activity, and attire of male and female students.

\section{METHODS}

Using content analysis, we examined images and videos from web materials collected during the 2014-15 
school year, aimed at prospective students, in a sample of 18 English-language Canadian engineering schools (out of a total of 38 such schools) representing a wide range of total enrolment, percent female enrolment, and region. The images and videos used here were collected together with the website text collected for earlier work examining gendered words in recruitment materials [2].

\subsection{Image Coding}

We collected 440 unique images containing one or more people from 17 schools (one school did not have any images of people). One coder completed all image coding. Each person in each image was coded for gender. Note that we are using outward gender presentation (and occasionally names, titles, and descriptive captions) to code for gender, and coding on a gender binary (rather than a spectrum), although we acknowledge that this may not capture all genders. Persons of unknown gender were coded as unknown. In larger groups, only persons who had visible faces and could be seen clearly were coded.

Each person was coded for role (student, instructor, industry), if this could be ascertained from situation, caption, etc., and otherwise coded as role unknown. Each person's setting (lab, classroom, worksite, etc.), activity (using tools, observing, posing, etc.), presence of business clothing, safety clothing, and safety headwear (e.g. hard hat, safety glasses) were coded. The composition of groups was obtained from analysis using the gender and image codes together. We also recorded if they were named, or their credentials were given (see Appendix A).

\subsection{Video Coding and Transcripts}

We collected and coded 37 videos from 11 schools. One coder (different from the images coder) coded all videos. In addition to gender, role, setting, activity, and other factors listed above, there was video-specific additional coding. Because one person could appear in various settings and activities, we coded up to three settings and/or activities for a single person appearing with the same group. We also coded for the screen time each person had, whether they spoke or not, and whether they narrated while off screen (see Appendix A).

We created transcripts of each video, and included the number of words spoken by various categories of people (e.g. male student, female instructor, male industry, etc.). We used inductive thematic coding to distinguish ways that male and female students shared their experience with prospective students, what aspects of their programs they highlighted to recruit students to their programs, and how they expressed their career aspirations.

\subsection{Engineers Canada Data}

Data for the gender composition of engineering disciplines and schools, including students and faculty members, was obtained from Engineers Canada data [1].

\subsection{Analysis}

All summary statistics were performed using STATA (StataCorp, College Station, Texas). Video transcripts were thematically coded using Nvivo (QSR International, Burlington, Massachusetts).

\section{RESULTS}

\subsection{Image results}

854 individuals were coded in 440 images (17 schools). These individuals were coded as students, instructors, people in industry, and people whose role was not determined, however in this paper we limit our analysis to students (Table 1).

Table 1: Distribution of people in images by role and gender in images.

\begin{tabular}{|l|c|c|c|c|}
\hline All images & Total & Male & Female & $\begin{array}{c}\text { \% female } \\
\text { in images }\end{array}$ \\
\hline Students & 491 & 357 & 134 & $27.3 \%$ \\
\hline
\end{tabular}

Women students were overrepresented in the images in comparison to actual gender composition of engineering programs. A median of $19.1 \%$ of students at these schools are women (range of 5.5-28.4\%) [1].

\section{Schools}

In images by school, women students were generally overrepresented $(0-75 \%$ of students in images) compared to what we expected to find based on their enrolment (5$28 \%$ of students in schools [1]; Table 2). Twelve out of 17 schools had a higher percentage of female students in images than enrolled. The schools at the extremes (3-5 times overrepresentation or zero images of women students) tended to have less than 5 images with students.

In fact, the number of women students depicted in images was not correlated with the proportion of women enrolled in a school $(p=0.08$ for all schools, $p=0.95$ for schools with at least 5 images including students).

\section{Disciplines}

Among disciplines, there was an overrepresentation of women students in images from most disciplines, with only Chemical, Industrial/Manufacturing, Software, and Other showing underrepresentation (Table 3). (Note that the "Other" category is defined by Engineers Canada, and 
includes Aerospace, Petroleum, Systems Design and other programs [1]).

Table 2: Students in images by school. Number of images with students (236 of 440 images), percent women students in images and percent women enrolled.

\begin{tabular}{|l|c|c|c|c|}
\hline & \multicolumn{2}{|c|}{ No. images } & \multicolumn{2}{c|}{$\%$ women } \\
\hline School & Total & $\begin{array}{c}\text { Among } \\
\text { Incl. } \\
\text { students }\end{array}$ & $\begin{array}{c}\text { Amonts } \\
\text { students } \\
\text { in } \\
\text { images }\end{array}$ & Enrolled \\
\hline Alberta & 18 & 18 & $19.0 \%$ & $20.0 \%$ \\
\hline BCIT & 2 & 2 & $50.0 \%$ & $9.3 \%$ \\
\hline Calgary & 3 & 3 & $75.0 \%$ & $24.2 \%$ \\
\hline Carleton & 62 & 47 & $29.9 \%$ & $13.9 \%$ \\
\hline Concordia & 9 & 5 & $44.4 \%$ & $19.6 \%$ \\
\hline Conestoga & 1 & 1 & $0 \%$ & $5.1 \%$ \\
\hline Dalhousie & 10 & 8 & $19.4 \%$ & $19.7 \%$ \\
\hline Manitoba & 10 & 5 & $45.5 \%$ & $17.7 \%$ \\
\hline McGill & 107 & 45 & $26.3 \%$ & $22.8 \%$ \\
\hline Memorial & 12 & 10 & $19.2 \%$ & $26.1 \%$ \\
\hline Regina & 5 & 3 & $75.0 \%$ & $23.0 \%$ \\
\hline SFU & 76 & 7 & $25.0 \%$ & $13.9 \%$ \\
\hline UBCO & 10 & 10 & $21.1 \%$ & $12.6 \%$ \\
\hline UBCV & 31 & 24 & $35.7 \%$ & $21.2 \%$ \\
\hline UNB & 35 & 30 & $22.6 \%$ & $15.4 \%$ \\
\hline UPEI & 9 & 3 & $0 \%$ & $14.2 \%$ \\
\hline Waterloo & 40 & 15 & $35.5 \%$ & $18.8 \%$ \\
\hline
\end{tabular}

Table 3: Students in images by discipline. Number of images with students, percent women in images and percent women enrolled.

\begin{tabular}{|l|c|c|c|c|}
\hline & \multicolumn{2}{|c|}{ No. images } & \multicolumn{2}{c|}{$\%$ women } \\
\hline Discipline & Total & $\begin{array}{c}\text { Among } \\
\text { Incl. } \\
\text { students }\end{array}$ & $\begin{array}{c}\text { students } \\
\text { in } \\
\text { images }\end{array}$ & Enrolled \\
\hline Biosys & 5 & 5 & $50.0 \%$ & $36.3 \%$ \\
\hline Chem & 11 & 8 & $18.2 \%$ & $34.9 \%$ \\
\hline Civil & 23 & 12 & $41.1 \%$ & $24.8 \%$ \\
\hline Comp & 12 & 8 & $18.2 \%$ & $11.6 \%$ \\
\hline Elec & 27 & 21 & $27.3 \%$ & $16.2 \%$ \\
\hline EngPhys & 6 & 4 & $33.3 \%$ & $11.8 \%$ \\
\hline Enviro & 7 & 6 & $57.1 \%$ & $39.0 \%$ \\
\hline Geo & 7 & 7 & $33.3 \%$ & $30.0 \%$ \\
\hline Indus/Man & 1 & 1 & $25.0 \%$ & $32.5 \%$ \\
\hline Materials & 5 & 3 & $40.0 \%$ & $20.6 \%$ \\
\hline Mech & 20 & 18 & $19.6 \%$ & $9.9 \%$ \\
\hline Mining & 9 & 5 & $18.5 \%$ & $13.5 \%$ \\
\hline Software & 9 & 7 & $9.1 \%$ & $10.2 \%$ \\
\hline Other & 16 & 11 & $14.3 \%$ & $20.9 \%$ \\
\hline
\end{tabular}

\section{Groups}

Women were more likely than we expected (based on enrolment numbers) to be depicted in images alone, but less likely to be included in group photos. Of the 99 images of students with only one person in them, $40 \%$ were of women.

There were 137 group images with students. Of these, $62(45 \%)$ were all male groups (2 to 7-person groups, with 24 groups of 3-7 men each), while only 5 (4\%) were all female groups (2-person groups only). Note that there were non-students in some images with students, and these were included in determining gender composition.

In mixed gender images with students (70 images), 35 images showed male-female pairs. Of the remaining 35 images of 3-20 individuals, 5 images had a majority of women (groups of 3-7), 29 had a majority of men (groups of 3-20), and 1 had equal numbers. Twenty-four images of 3 or more people had only one woman.

In sum, the most common image grouping involved a mixed group $(30 \%)$, followed by a group of men $(26 \%)$ and single men $(25 \%)$, however $19 \%$ of images involved women only.

\section{Settings}

We found that there were more female students in irrelevant settings than male students (53\%), despite having fewer overall images of women (Table 4). Relevant settings included laboratories, classrooms, worksites, and other settings related to engineering, while irrelevant settings included places such as campus lawns, lounges, coffee shops, etc.

Table 4: Relevance of settings by male and female students in images.

\begin{tabular}{|l|c|c|c|}
\hline \multicolumn{1}{|c|}{ Students } & Men & Women & $\begin{array}{c}\% \\
\text { female }\end{array}$ \\
\hline Relevant setting & 340 & 115 & $25 \%$ \\
\hline Irrelevant setting & 17 & 19 & $53 \%$ \\
\hline
\end{tabular}

When examining specific relevant settings, women students appeared in similar proportions to the images overall (Table 5).

Table 5: Specific relevant settings by male and female students and non-students in images.

\begin{tabular}{|l|c|c|c|}
\hline \multicolumn{1}{|c|}{ Students } & Men & Women & $\begin{array}{c}\% \\
\text { female }\end{array}$ \\
\hline Laboratory & 134 & 56 & $29 \%$ \\
\hline Classroom & 26 & 10 & $27 \%$ \\
\hline Worksite & 23 & 10 & $30 \%$ \\
\hline
\end{tabular}

\section{Activities}

Among students using a computer, tablet or smartphone, there were fewer women than expected given their representation in images, however among students guiding others, there were more women than expected. 
Women were well represented using machines and tools and writing, and underrepresented in observing others (Table 6).

Table 6: Specific activities by male and female students and non-students in images.

\begin{tabular}{|l|c|c|c|}
\hline \multicolumn{1}{|c|}{ Students } & Men & Women & $\begin{array}{c}\% \\
\text { female }\end{array}$ \\
\hline $\begin{array}{l}\text { Using } \\
\text { computer/mobile } \\
\text { device }\end{array}$ & 19 & 4 & $17 \%$ \\
\hline $\begin{array}{l}\text { Using } \\
\text { machine/tool }\end{array}$ & 79 & 39 & $33 \%$ \\
\hline Writing & 11 & 5 & $31 \%$ \\
\hline Guiding & 6 & 4 & $40 \%$ \\
\hline Observing & 67 & 19 & $22 \%$ \\
\hline Posing & 140 & 49 & $26 \%$ \\
\hline
\end{tabular}

\section{Attire}

Among students wearing business attire, only $9 \%$ were women. On the other hand, among students wearing head and especially body safety equipment/clothing, women made up a higher proportion than in overall images (Table 7).

Table 7: Attire by male and female students and nonstudents in images.

\begin{tabular}{|l|c|c|c|}
\hline \multicolumn{1}{|c|}{ Students } & Men & Women & $\begin{array}{c}\% \\
\text { female }\end{array}$ \\
\hline $\begin{array}{l}\text { Safety attire on } \\
\text { head (glasses, hard } \\
\text { hat) }\end{array}$ & 34 & 15 & $31 \%$ \\
\hline $\begin{array}{l}\text { Safety attire on } \\
\text { body }\end{array}$ & 34 & 20 & $37 \%$ \\
\hline Business clothes & 74 & 7 & $9 \%$ \\
\hline
\end{tabular}

\section{Names/credentials}

Women students were slightly less likely to be named or to have credentials given compared to their presence in the images overall (Table 8).

Table 8: Names or credentials given for students and nonstudents by gender in images.

\begin{tabular}{|l|c|c|c|}
\hline \multicolumn{1}{|c|}{ Students } & Men & Women & $\begin{array}{c}\% \\
\text { female }\end{array}$ \\
\hline Named & 36 & 11 & $23 \%$ \\
\hline Credentials given & 21 & 7 & $25 \%$ \\
\hline
\end{tabular}

\subsection{Video results}

1477 individuals were coded in separate scenes in 37 videos (11 schools). These individuals were coded as students, instructors, people in industry, and people whose role was not determined; in this paper we are presenting student results only (Table 9). Again, women students appeared well above their proportion at these schools (median 17.8\%) [1].

Table 9: Distribution of people by role and gender in videos.

\begin{tabular}{|l|c|c|c|c|}
\hline All images & Total* & Male & Female & $\begin{array}{c}\text { \% female } \\
\text { in videos }\end{array}$ \\
\hline Students & 1177 & 831 & 346 & $29.3 \%$ \\
\hline
\end{tabular}

*125 students appeared more than once in a video (up to five times), and were coded with the same person code but a separate line/scene.

\section{Schools}

Nine out of 11 schools with videos overrepresented women in their videos, up to about 3.5 times the actual proportion (Table 10). It should be noted that Carleton University produced an entire video on women in engineering, which may account for the near parity in student gender in their videos.

Table 10: Students in videos by school. Number of videos, total words spoken per video, total students in videos, percent women students in videos and enrolled.

\begin{tabular}{|l|c|c|c|c|c|}
\hline & \multicolumn{3}{|c|}{$\begin{array}{c}\text { No. videos, total } \\
\text { words, total } \\
\text { students }\end{array}$} & \multicolumn{2}{c|}{$\%$ women } \\
\hline School & No. & $\begin{array}{c}\text { Total } \\
\text { words }\end{array}$ & $\begin{array}{c}\text { Tot. } \\
\text { stu. }\end{array}$ & $\begin{array}{c}\text { Among } \\
\text { stud. in } \\
\text { videos }\end{array}$ & $\begin{array}{c}\text { En- } \\
\text { rolled }\end{array}$ \\
\hline BCIT & 2 & 635 & 15 & $6.3 \%$ & $9.3 \%$ \\
\hline Calgary & 1 & 278 & 26 & $38.5 \%$ & $24.2 \%$ \\
\hline Carleton & 10 & 4320 & 136 & $47.1 \%$ & $13.9 \%$ \\
\hline Concordia & 1 & 421 & 64 & $31.3 \%$ & $19.6 \%$ \\
\hline Conestoga & 3 & 2043 & 55 & $20.0 \%$ & $5.1 \%$ \\
\hline Manitoba & 1 & 1212 & 121 & $21.5 \%$ & $17.8 \%$ \\
\hline McGill & 2 & 997 & 97 & $33.0 \%$ & $22.8 \%$ \\
\hline Memorial & 7 & 5549 & 487 & $26.5 \%$ & $26.1 \%$ \\
\hline SFU & 3 & 999 & 1 & $0 \%$ & $13.9 \%$ \\
\hline UNB & 4 & 1031 & 60 & $28.3 \%$ & $14.3 \%$ \\
\hline UPEI & 3 & 1151 & 115 & $31.3 \%$ & $18.8 \%$ \\
\hline
\end{tabular}

\section{Disciplines}

Six of 11 schools did not produce discipline specific videos, some schools had videos for some disciplines and not others (e.g. UNB had a video for 1 out of 9 disciplines offered), and the coding of individuals by discipline in general engineering videos was only possible if they were identified in the video as being part of a particular department or program. Since any analysis by discipline would be heavily influenced by a handful of schools, this analysis was omitted for the video coding.

\section{Groups}

In order to look at the composition of groups, each scene in the video (clearly connected images of the same setting/activity/group) was coded. There were 671 
individual scenes in the 37 videos, of which 542 scenes $(81 \%)$ involved students. Some students appeared in more than one scene.

Similar to the image results, women made up $35 \%$ of students among scenes with only one student (216 scenes), more than their overall prevalence in the videos. There were 326 group scenes with students., Of these, 123 $(38 \%)$ had men only (2-10 people), while 26 scenes $(8 \%)$ had women only (2-8 people).

Out of 177 mixed gender scenes, 41 were pairs (1 man, 1 woman), 21 had a majority of women (groups of 3-11), 23 had equal numbers (groups of 4-6), and 92 had a majority of men (groups of 3-19). 55 of the 136 mixed gender scenes with 3 or more people included only one woman. Once again, non-students were in these scenes and contributed to determining the gender composition.

In sum, the most common composition of a scene with students was a mixed gender group (33\%), followed by a scene of a single male student $(26 \%)$ and a group of males $(23 \%)$. However, given the low proportion of women in engineering across all schools, women were more prominent in video scenes than expected, with $19 \%$ of scenes involving women only.

\section{Settings}

The types of settings coded were the same as in the images, however since a person could be shown in multiple settings, up to three settings were coded per person.

Female students made up a larger percentage of students in irrelevant settings $(46 \%)$ than expected by their presence in the videos overall (Table 11).

Table 11: Relevance of settings by male and female students in videos.

\begin{tabular}{|l|c|c|c|}
\hline \multicolumn{1}{|c|}{ Students } & Men & Women & $\begin{array}{c}\% \\
\text { female }\end{array}$ \\
\hline Relevant setting & 720 & 262 & $27 \%$ \\
\hline Irrelevant setting & 92 & 77 & $46 \%$ \\
\hline
\end{tabular}

When considering specific settings for each person and all appearances in the videos, women made up $28 \%$ and $27 \%$ of students in labs and classrooms, but only $14 \%$ of students at worksites (Table 12).

Table 12: Relevance of settings by male and female students in videos (all settings included).

\begin{tabular}{|l|c|c|c|}
\hline \multicolumn{1}{|c|}{ Students } & Men & Women & \% female \\
\hline Laboratory & 489 & 193 & $28 \%$ \\
\hline Classroom & 169 & 62 & $27 \%$ \\
\hline Worksite & 19 & 3 & $14 \%$ \\
\hline
\end{tabular}

\section{Activities}

Women students were more likely to be depicted writing or guiding others, and less likely to be using computers, smartphones, or tablets. (Table 13).

Table 13: Specific activities by male and female students in videos.

\begin{tabular}{|l|c|c|c|}
\hline \multicolumn{1}{|c|}{ Students } & Men & Women & \% female \\
\hline $\begin{array}{l}\text { Using } \\
\text { computer/mobile } \\
\text { device }\end{array}$ & 86 & 24 & $22 \%$ \\
\hline $\begin{array}{l}\text { Using } \\
\text { machine/tool }\end{array}$ & 246 & 83 & $25 \%$ \\
\hline Writing & 16 & 12 & $43 \%$ \\
\hline Guiding & 19 & 12 & $39 \%$ \\
\hline Observing & 338 & 147 & $30 \%$ \\
\hline Posing & 73 & 38 & $34 \%$ \\
\hline
\end{tabular}

Attire

Women were more likely to wear safety attire on their bodies, but were less likely to wear business attire (although not as unlikely as in images) (Table 14).

Table 14: Attire by male and female students in videos.

\begin{tabular}{|l|c|c|c|}
\hline \multicolumn{1}{|c|}{ Students } & Men & Women & $\begin{array}{c}\% \\
\text { female }\end{array}$ \\
\hline $\begin{array}{l}\text { Safety attire on } \\
\text { head (glasses, hard } \\
\text { hat) }\end{array}$ & 153 & 49 & $24 \%$ \\
\hline $\begin{array}{l}\text { Safety attire on } \\
\text { body }\end{array}$ & 94 & 61 & $39 \%$ \\
\hline Business clothes & 135 & 44 & $25 \%$ \\
\hline
\end{tabular}

\section{Names/credentials}

In the videos, if a person was named, their credentials were given in almost every case (Table 15). Among students who were named, $43 \%$ were female, well above their presence in the videos.

Table 15: Names or credentials given for students in videos.

\begin{tabular}{|l|c|c|c|}
\hline \multicolumn{1}{|c|}{ Students } & Men & Women & $\begin{array}{c}\text { \% } \\
\text { female }\end{array}$ \\
\hline Named & 48 & 36 & $43 \%$ \\
\hline Credentials given & 46 & 36 & $44 \%$ \\
\hline
\end{tabular}

\section{Video-specific (speaking, narrating, and screen time)}

Screen time was determined by an indication of time an individual remained visible in the scene (Table 16). Women were overrepresented among students who remained on screen for longer periods of time.

Among students who spoke and narrated while offscreen, women made up $45 \%$ and $49 \%$ respectively, well above their rate of appearance in the videos (Table 17). 
Table 16: Screen time for students by gender in videos.

\begin{tabular}{|l|c|c|c|}
\hline \multicolumn{1}{|c|}{ Students } & Men & Women & $\begin{array}{c}\% \\
\text { female }\end{array}$ \\
\hline$<2$ seconds & 272 & 104 & $28 \%$ \\
\hline$<5$ seconds & 498 & 217 & $30 \%$ \\
\hline$<10$ seconds & 72 & 37 & $34 \%$ \\
\hline $10-30$ seconds & 49 & 31 & $39 \%$ \\
\hline$>30$ seconds & 8 & 9 & $53 \%$ \\
\hline$>1$ minute & 4 & 1 & $20 \%$ \\
\hline
\end{tabular}

Table 17: Speaking and narrating when off-screen for students and non-students by gender in videos.

\begin{tabular}{|l|c|c|c|}
\hline \multicolumn{1}{|c|}{ Students } & Men & Women & $\begin{array}{c}\% \\
\text { female }\end{array}$ \\
\hline Speak & 69 & 57 & $45 \%$ \\
\hline Narrate & 37 & 36 & $49 \%$ \\
\hline
\end{tabular}

\subsection{Video transcripts}

\section{Words spoken}

The words spoken were coded by gender and role in each video (Table 18). In addition to the roles already described, the role of narrator was also coded. Again, we are presenting student results only.

The words spoken by gender show a huge range among the groups. Female students have nearly a third more words in proportion to their overall presence in the videos. This was not solely a reflection of the "women in engineering" video as there were 21 videos with words spoken by female students (total 29 - 563 female student words per video) and 24 videos with words spoken by male students (total 29 - 1264 male student words per video). Only 14 videos had words spoken by both male and female students.

Table 18: Distribution of words spoken by gender in videos.

\begin{tabular}{|l|c|c|c|c|}
\hline All videos & $\begin{array}{c}\text { Total } \\
\text { words } \\
\text { spoken }\end{array}$ & Male & Female & $\begin{array}{c}\text { \% female } \\
\text { spoken } \\
\text { words }\end{array}$ \\
\hline Students & 9535 & 5522 & 4013 & $42.1 \%$ \\
\hline
\end{tabular}

\section{Career Aspirations}

In terms of videos' spoken content, male and female students expressed their career aspirations in decidedly different ways. Male students referred to specific careers and job roles (i.e. video game designer) alternating with indications that they wanted jobs that would allow them to "use [their] talents in math and science." Female students also referenced specific jobs (i.e. professor, working in the aerospace industry), but far more frequently referenced "helping" professions, such as "build[ing] sustainable communities in third world countries" and "mak[ing] a difference in the field of medical technology" and "help[ing] everybody reduce their carbon footprint."

\section{Experience}

There is a great deal of similarity in emphasis on skill attainment, and opportunities to learn through co-op and other experiential learning opportunities, however women and men differ in how they discuss other aspects of their education experiences. Men are much more likely to comment on the experience of working in teams to prepare for examinations, having unfettered access to professors, and the value of competition to encourage their learning. Women students on the other hand refer to experiential learning opportunities as the cornerstone of their education, and to focus on the support that they receive through participation in co-curricular activities. An exception to this was the targeted support women received through different gender-focused programs, like Women in Science and Engineering (WISE). References to these programs reflected that women students were on some level self-conscious of their role as women engineers (i.e. "When I [arrived] I realized that there is so much attention being paid to the fact that you're a woman and [involved] in science and engineering, which is very good." And "I think it's important because we bring a lot to the table. I mean we have good ideas, we're creative, patient. There's a lot of good qualities that women can bring to the table.")

\section{DISCUSSION}

Due to the heightened awareness of gender inequalities in engineering, we expected that the images and videos would over represent women students and show them in generally positive ways, and it does appear that Canadian engineering schools are generally including more imagery of women than the student body composition would suggest, with no overt bias. It is important to examine, however, the results of implicit bias that may be expressed through the selection of images.

The images and videos analyzed here tend to over represent female students, but typically do not reach gender parity. In the videos, women students were named at a higher rate than they appeared in the videos, and a much higher rate than their enrolment would suggest. They also made up a large percentage of students at the highest screen time and those who spoke or narrated while off-screen, and spoke a large proportion of words by students. This high representation, combined with the kind of things women and men either chose to talk about or were directed to address, suggests that videos were produced in part as a way to reinforce messages about programs and schools being aware of the need to provide social support, especially to women students. Highlighting the experience of women students may have been a strategic decision schools use as an attempt to increase female enrolment rates and to address underlying concerns women might have about entering a maledominated field. 
In terms of picture composition, it does not appear that there is intentional tokenism occurring in the imagery, where efforts are made to add a woman to otherwise all male groups for the sake of appearance. While there were many images and scenes of mixed groups of 3 or more with only one woman, about $14 \%$ (images) and $15 \%$ (scenes) of mixed groups had more female than male members. However, there were many groups of only men, and they tended to be larger than groups of only women.

Among students, women were photographed in settings irrelevant to engineering at a higher proportion than their overall presences predicts, either in actual enrolment or in their percent inclusion in the images. The same outcome was seen in the videos, with even higher numbers of students involved. The cause of this difference is not clear, but the result is of interest. If female students are more likely to be shown in a coffee shop or on a campus lawn than male students, the message of women belonging in engineering spaces could be contradicted by the imagery presented. In similar research, women were more likely than men to be shown in 'non-job locations' in images in corporate annual reports for large accounting firms [3].

Among students wearing business attire in images, only a small fraction (9\%) were women, well below the typical proportion of women in the images $(25 \%$ in videos, slightly below their proportion). Business attire is a marker for importance and authority, so the lack is notable. For example, students perceive university professors wearing formal attire to be more credible than those wearing less formal clothing [4]. This finding is also consistent with images in corporate annual reports for large accounting firms where men are more likely than women to be shown dressed in 'work' attire instead of 'casual' attire [3].

Women students were more often wearing safety clothing in images than their proportion in all images would suggest. It is unclear what this represents, but it may be an intentional effort to identify women as belonging in engineering, or could possibly reflect an implicit perception of women as safety-conscious. Research shows that television scientists are bestowed special status based partly on their clothing (e.g. lab coats) [5]-[8], and the safety wear (hard hats, etc.) maybe represent a similar marker of status for engineering.

Overall, women students were generally included in imagery at rates over their measured participation in schools and faculties, and in a range of settings and activities. However, when examining specific markers of belonging in engineering, such as relevant settings, types of activities, and the wearing of safety equipment or business clothing, the results were more mixed.

It is admirable that schools want to work to attract female students to their programs, but efforts should be carefully considered to ensure that the presentation of women in engineering programs does not cultivate a tiered system where women are primarily visible in particular spaces and doing particular activities, or where women alone are responsible for addressing gender inequities (as in their promotion of women in engineering support groups). One way for programs to shift from the possibility of creating a tiered system is to focus on and celebrate the women-identified goals of using engineering to make positive social impacts in society. By expanding this conversation to the ways that all engineers (male and female) contribute to helping improve society, programs will embody the values that attract women, while shifting the perception of engineering in a direction that will have multiple benefits.

We hope that this analysis will provide engineering schools with specific factors to consider when creating images and videos aimed at prospective students.

\section{Acknowledgements}

We would like to acknowledge Westcoast Women in Engineering, Science, and Technology (WWEST) and the UBC Department of Mechanical Engineering for providing funding and resources for this project.

\section{References}

[1] Engineers Canada, "Canadian Engineers for Tomorrow: Trends in Engineering Enrolment and Degrees Awarded 2009-2013," 2014.

[2] A. G. d'Entremont, K. Greer, and K. A. Lyon, "Gendered Words in Canadian Engineering Recruiment Documents," in Proc. 2015 Canadian Engineering Education Association (CEEA15) Conf., 2015, pp. 1-7.

[3] A. Duff, "Big four accounting firms' annual reviews: A photo analysis of gender and race portrayals," Crit. Perspect. Account., vol. 22, no. 2011, pp. 20-38, 2010.

[4] K. Lightstone, R. Francis, and L. Kocum, "University Faculty Style of Dress and Students' Perception of Instructor Credibility," Int. J. Bus. Soc. Sci., vol. 2, no. 15, pp. 15-22, 2011.

[5] J. Steinke and M. Long, "A Lab of Her Own? Portrayals of Female Characters on Children's Educational Science Programs," Sci. Commun., vol. 18, no. 2, pp. 91-115, 1996.

[6] M. Long, G. Boiarsky, and G. Thayer, "Gender and racial counter-stereotypes in science education television: a content analysis," Public Underst. Sci., vol. 10, pp. 255-269, 2001.

[7] M. Long and J. Steinke, "The thrill of everyday science: images of science and scientists on children 's educational science programmes in the United States," Public Underst. Sci., vol. 5, pp. 101-119, 1996.

[8] S. Hornig, "Television's NOVA and the construction of scientific truth," Crit. Stud. Mass Commun., no. 7, pp. 11-23, 1990. 


\section{APPENDIX A: CODING LISTS}

\section{A.1 Images coding}

Each image was given a unique code, and each person in the image was given a unique code. Further coding details can be found in section A.3.

\section{A.2 Video coding}

Each video was given a unique code, each scene in the video was given a unique code (primarily for assessing groups of people appearing together in a video), and each person in the video was given a unique code.

Due to the nature of video, a person could be shown doing more than one activity in a scene, or shown in more than one setting. Up to three activities or settings were coded for each person.

Additional coding related to video was performed (Table A1), as well as screen time (see Table 16). Further coding details can be found in section A.3.

Table A1: Coding for speaking and narration in videos.

\section{Speaking, narrating}

Y/N $\quad$ Do they speak?

$\mathrm{Y} / \mathrm{N}$ Is the person's voice used to narrate while they are not on screen?

\section{A.3 Common coding for both images and videos}

Many aspects of the imagery were coded in the same way for both images and videos. The engineering discipline for each individual was coded based on the Engineers Canada disciplines, which names every Canadian engineering program title that falls under each discipline. If no discipline was given on the webpage or in the video, the person was coded as general engineering.

We coded individuals whose gender was unknown, but removed them for the analysis in this paper (Table A2).

Table A2: Coding for gender and role.

\begin{tabular}{|c|l|}
\hline \multicolumn{2}{|c|}{ Gender and role } \\
\hline 1 & Male student \\
\hline 2 & Female student \\
\hline 3 & Male instructor/faculty member \\
\hline 4 & Female instructor/faculty member \\
\hline 5 & Male industry \\
\hline 6 & Female industry \\
\hline 7 & Male unknown role \\
\hline 8 & Female unknown role \\
\hline 9 & Gender unknown student \\
\hline 10 & Gender unknown instructor/faculty member \\
\hline 11 & Gender unknown industry \\
\hline 12 & Gender unknown, unknown role \\
\hline
\end{tabular}

Table A3: Coding for setting.

\begin{tabular}{|c|l|}
\hline \multicolumn{2}{|c|}{ Setting } \\
\hline 1 & Lab/workshop \\
\hline 2 & Classroom \\
\hline 3 & $\begin{array}{l}\text { Worksite (e.g. mine, construction site, shipyard, } \\
\text { manufacturing plant) }\end{array}$ \\
\hline 4 & $\begin{array}{l}\text { Other relevant location (e.g. at a competition, on } \\
\text { exchange) }\end{array}$ \\
\hline 5 & Irrelevant location (e.g. coffee shop) \\
\hline 6 & Other (specify) \\
\hline
\end{tabular}

Table A4: Coding for activity.

\begin{tabular}{|c|l|}
\hline \multicolumn{2}{|c|}{ Activity } \\
\hline 1 & Using computer/smartphone/tablet \\
\hline 2 & Using machine/tool (e.g. lab equipment) \\
\hline 3 & Writing (not on a computer) \\
\hline 4 & Guiding/instructing others \\
\hline 5 & Observing \\
\hline 6 & Posing for award/ceremony/with tool or machine \\
\hline 7 & Posing passively for the camera \\
\hline 8 & Other (specify) \\
\hline
\end{tabular}

Table A5: Coding for attire, names and credentials.

\begin{tabular}{|c|l|}
\hline \multicolumn{2}{|c|}{ Attire, names, credentials } \\
\hline Y/N & Name provided? \\
\hline Y/N & Title/credentials provided? \\
\hline Y/N & $\begin{array}{l}\text { Wearing safety equipment on head/face? (e.g. } \\
\text { goggles, hardhat, mask, respirator) }\end{array}$ \\
\hline Y/N & $\begin{array}{l}\text { Wearing safety equipment on body? (e.g. lab } \\
\text { coat, work jump suit, scrubs, safety vest, work } \\
\text { gloves) }\end{array}$ \\
\hline Y/N & Wearing business attire? \\
\hline
\end{tabular}

\section{A.4 Video transcripts}

Videos also have narration, so in addition to the gender and role coding listed in section A.3, we identified male and female narrators who were not shown on screen during the video. 